\title{
STUDI DESKRIPTIF TINGKAT PENGETAHUAN SUAMI TENTANG KONTRASEPSI KONDOM DI RW XIII KELURAHAN SENDANGMULYO KECAMATAN TEMBALANG KOTA SEMARANG
}

\author{
DESCRIPTIVE STUDY OF THE LEVEL OF KNOWLEDGE ABOUT HUSBAND \\ CONDOMS CONTRACEPTION IN SUB RW XIII VILLAGE SENDANGMULYO \\ CITY SEMARANG TEMBALANG
}

\author{
Sherkia Ichtiarsi Prakasiwi \\ Program Studi DIII Kebidanan Fakultas Ilmu Keperawatan dan Kesehatan, \\ Universitas Muhammadiyah Semarang \\ Email : sherkia@unimus.ac.id
}

\begin{abstract}
ABSTRAK
Berdasarkan data BKKBN tingkat penggunaan kondom pada laki - laki masih sangat rendah, hanya 1,3 persen dari akseptor $K B$, dan pencapaian peningkatan penggunaan kondom pada pasangan usia subur tahun 2017 pun belum sesuai target. Pemerintah menargetkan pengguna kondom meningkat 300 persen dari tahun 2015, menjadi 976 ribu pada 2017. Namun, hingga saat ini peningkatannya baru mencapai 41 persen. Jumlah pengguna kondom untuk peserta baru KB per September 2017 di Indonesia hanya mencapai 58.757, berada di nomor tiga setelah KB suntikan 302.459 dan pil 186.439. Tujuan dari penelitian ini adalah untuk mengetahui tingkat pengetahuan suami tentang kontrasepsi kondom di RW XIII Kelurahan Sendangmulyo Kecamatan Tembalang Kota Semarang. Penelitian yang digunakan adalah penelitian deskriptif dengan populasinya adalah seluruh suami yang bertempat tinggal di RW XIII Kelurahan Sendangmulyo. Sampel yang digunakan yaitu 45 responden dengan cara sample random sampling. Instrumen penelitan menggunakan kuesioner. Variabel yang diteliti adalah tingkat pengetahuan suami tentang kontrasepsi kondom. Hasil validitas pada 10 responden dari 20 item didapatkan hasil $r_{\text {hitung }}>r_{\text {tabel }}, r_{\text {tabel }}$ yaitu 0,632 sehingga hasilnya valid dan reliabel karena hasil Alfa Crobanch 0,965. Hasil penelitian menunjukkan pengetahuan suami tentang kontrasepsi kondom di $R W$ XIII Kelurahan Sendangmulyo Kecamatan Tembalang Kota Semarang yang berpengetahuan cukup sebanyak 26 orang (57,8\%), berpengetahuan baik 18 orang (40\%) dan pengetahuan kurang satu orang $(2,2 \%)$.
\end{abstract}

Kata kunci : :Tingkat Pengetahuan, Suami, Kontrasepsi Kondom

\section{ABSTRACT}

Based on the BKKBN data rates of condom use in men - men are still very low, only 1.3 percent of the acceptors of family planning and the achievement of increased use of condoms to couples of childbearing age in the year 2017 was not the right target. The Government aims condom users increased 300 percent from the year 2015, 976000 in 2017. However, until now has only reached 41 percent improvement. The number of condom users to new participants in the September 
2017 Family Planning in Indonesia only reached 58 757, situated at number three after the injections and pills KB 186.439 and 186.439. The purpose of this study was to determine the level of knowledge about contraception condoms husband in $R W$ XIII Sendangmulyo Village Tembalang Semarang District. Population research is descriptive research is that all husbands who live in Kelurahan Sendangmulyo $R W$ XIII. The sample used was a random sample of 45 respondents. Research using a questionnaire instrument. Variables examined were the level of knowledge about contraception condoms husband. Results of validity in 10 respondents from 20 items results, namely 0.632 rtabel so the results are valid>rtabel rhitung and reliable because the results of Alfa Crobanch 0.965. Results showed that knowledge about contraceptives husband RW XIII enough condoms in the village, Semarang regency Tembalang Sendangmulyo knowledgeable as many as 26 people (57.8\%), knowledge, and 18 people (40\%) and knowledge of one person (2.2\%). We ask members of the RW PLKB Village Health Worker Tembalang Sendangmulyo District XIII provides counseling counseling and counseling about the benefits - the benefits of condoms contraceptives to eliminate a bad public perception about condoms.

Keywords : Level of Knowledge, Husband, Contraception Condoms

\section{PENDAHULUAN}

Sejak program Keluarga Berencana ( KB ) digulirkan untuk menahan laju penduduk, perempuan menjadi sasaran utama untuk menjadi akseptor. Padahal keikutsertaan pria sebagai pasangan prempuan juga diharapkan untuk mengimbangi keikutsertaan perempuan sebagai akseptor KB.

Rendahnya kesertaan KB Pria di Indonesia pada umumnya disebabkan oleh empat hal yaitu: (1) Kurangnya promosi, sosialisasi dan KIE KB Pria, (2) Terbatasnya sarana dan prasarana, dana dan sumber daya manusia untuk pelayanan KB Pria khususnya MOP, (3) Kurang optimalnya dukungan stakeholder dan shareholder (kemitraan) untuk program KB Pria, (4) Masih banyaknya hambatan dari sisi sosial, budaya dan agama dalam upaya lebih memasyarakatkan Kondom dan MOP sebagai alat kontrasepsi andalan pria. Hal tersebut dapat berdampak negatif terhadap manfaat alat kontrasepsi kondom itu sendiri, yakni cakupan Pemerintah terhadap KB Pria tidak tercapai, dan penularan IMS-HIV/AIDS bisa semakin merajalela (Mardiyo, 2014).

Jumlah pengguna kondom untuk peserta baru KB per September 2017 di Indonesia hanya mencapai 58.757 , berada di nomor tiga setelah KB suntikan 302.459 dan pil 186.439 (BKKBN online, 2017). Menurut data di Jawa Tengah peserta KB berjumlah 643.596 dengan rincian Suntik 403.354 (62,67\%), Pil 111.697 (17,36\%), Implan 62.384 (9,69\%), Kondom 29.586 (4,60\%), AKDR sebanyak 23.763 (3,64\%), MOW 11.884 (1,85\%), dan MOP 928 (0,14\%). Di Kota Semarang sendiri jumlah akseptor KB sebanyak 19.658, dengan pengguna KB Suntik sebanyak 12.566 (63,92\%), Implan 3.658 (18,61\%), Pil 1696 (8,63\%), AKDR $1.171(5,96 \%)$, MOW 285 (1,45\%), Kondom 260 (1,32\%), MOP 22 (0,11\%). Pengguna KB Kondom menempati urutan kedua terendah diantara pengguna KB lainnya.

Menurut data di Kelurahan Sendangmulyo hingga Desember 2016, jumlah penduduk pada Kelurahan tersebut berjumlah 28.800 orang. Jumlah Pasangan 
Usia Subur (PUS) 2605 pasangan. Sedangkan jumlah Suami di Kelurahan Sendangmulyo berjumlah 2605 suami. Dengan pengguna KB Suntik sebanyak 1373 akseptor, Pil 482 akseptor, AKDR 260 akseptor, Implant 163 akseptor, MOW 144 akseptor, Kondom 131 akseptor, dan MOP 44 akseptor. Data tersebut menunjukkan alat kontrasepsi Kondom kurang diminati oleh Penduduk Kelurahan Sendangmulyo karena jumlah pemakaian Kondom hanya sejumlah $131(5,02 \%)$ akseptor saja. Hal tersebut belum memenuhi target yang diinginkan yaitu sebesar $74,43 \%$.

Di RW XIII sendiri hingga Januari 2017 tercatat ada 525 jumlah KK (Kepala Keluarga), Jumlah PUS sebanyak 213, dan jumlah suami sendiri sebanyak 213 orang. Peserta KB Aktif tercatat ada 135 dengan rincian Akseptor KB Suntik sebanyak 44 akseptor, Pil 35 akseptor, MOW 16 akseptor, IUD 14 akseptor, Implant 10 akseptor, Kondom 11 Akseptor, dan MOP 5 akseptor. Kondom menempati urutan kedua terbawah setelah MOP, terbukti dengan jumlah pengguna Kondom hanya sejumlah 11 akseptor saja atau sekitar 8,14\%. Hal tersebut belum memenuhi target cakupan yang telah ditentukan yakni sebesar $72,5 \%$.

\section{METODE PENELITIAN}

Penelitian yang digunakan adalah penelitian deskriptif dengan populasinya adalah seluruh suami yang bertempat tinggal di RW XIII Kelurahan Sendangmulyo. Sampel yang digunakan yaitu 45 responden dengan cara sample random sampling. Instrumen penelitan menggunakan kuesioner. Variabel yang diteliti adalah tingkat pengetahuan suami tentang kontrasepsi kondom . Hasil validitas pada 10 responden dari 20 item didapatkan hasil $r_{h i t u n g}>r_{\text {tabel }}, r_{\text {tabel }}$ yaitu 0,632 sehingga hasilnya valid dan reliabel karena hasil Alfa Crobanch 0,965.

\section{HASIL DAN PEMBAHASAN}

1. Karakteristik Responden

a. Karakteristik Responden Berdasarkan Umur

Tabel Distribusi frekuensi responden berdasarkan umur di RW XIII.

\begin{tabular}{ccc}
\hline Umur & Frekuensi (n) & Prosentase (\%) \\
\hline$<20$ tahun & 2 & 4 \\
$20-30$ tahun & 31 & 69 \\
$>30$ tahun & 12 & 27 \\
\hline Jumlah & 45 & 100,0 \\
\hline Sumber : Data Primer & &
\end{tabular}

Mayoritas responden penelitian ini berumur 20-30 tahun yaitu sebanyak 31 orang $(69 \%)$, dan yang berumur $>30$ tahun sebanyak 12 orang $(27 \%)$ sedangkan yang berumur $<20$ tahun hanya sebanyak dua orang $(4 \%)$.

b. Karakteristik Responden Berdasarkan Pendidikan

Tabel Distribusi frekuensi responden berdasarkan pendidikan di RW XIII.

\begin{tabular}{ccc}
\hline Pendididan & Frekuensi (n) & Prosentase $(\%)$ \\
\hline
\end{tabular}




\begin{tabular}{ccc}
\hline Tidak sekolah & 0 & 0 \\
Tamat SD & 1 & 2 \\
Tamat SMP & 13 & 29 \\
Tamat SMA & 20 & 45 \\
Tamat Perguruan Tinggi & 11 & 24 \\
\hline Jumlah & 45 & 100,0 \\
\hline
\end{tabular}

Sumber : Data Primer

Tingkat pendidikan responden pada penelitian ini mayoritas tamat SMA yakni sebesar 20 orang (45\%), yang lain-lain adalah tamat SMP 13 orang (29\%), dan yang tamat perguruan tinggi sebanyak 11 orang $(24 \%)$, tamat SD satu orang $(2 \%)$ dan yang tidak bersekolah tidak ada.

c. Karakteristik Responden Berdasarkan Pekerjaan

Tabel Distribusi frekuensi responden berdasarkan pekerjaan di RW XIII.

\begin{tabular}{ccc}
\hline Pekerjaan & Frekuensi (n) & Prosentase (\%) \\
& & 38 \\
PNS & 16 & 59 \\
Swasta & 25 & 3 \\
Buruh & 4 & 0 \\
Lain-lain & 0 & 100,0 \\
\hline Jumlah & 45 & \\
\hline
\end{tabular}

Sumber : Data Primer

Untuk pekerjaan para responden di RW XIII mayoritas adalah swasta 25 orang (59\%), dan yang bermata pencaharian sebagai PNS 16 orang $(38 \%)$ dan yang bermata pencaharian buruh hanya empat orang saja $(3 \%)$.

d. Karakteristik Responden Berdasarkan Alat Kontrasepsi yang sedang digunakan

Tabel Distribusi frekuensi responden berdasar Alat Kontrasepsi yang sedang digunakan di RW XIII.

\begin{tabular}{ccc}
\hline $\begin{array}{c}\text { Alat Kontrasepsi yang } \\
\text { sedang digunakan }\end{array}$ & Frekuensi (n) & Prosentase (\%) \\
\hline $\begin{array}{c}\text { Kondom } \\
\text { MOP }\end{array}$ & 4 & 9 \\
$\begin{array}{c}\text { Suami tidak menggunakan } \\
\text { kontrasepsi (istri yang } \\
\text { menggunakan) }\end{array}$ & 0 & 89 \\
$\begin{array}{c}\text { Suami tidak menggunakan } \\
\text { kontrasepsi apapun (istri } \\
\text { juga tidak menggunakan) }\end{array}$ & 1 & 2 \\
\hline Jumlah & & \\
\hline
\end{tabular}

Sumber : Data Primer

Untuk alat kontrasepsi yang digunakan oleh para responden sebagian besar adalah suami tidak menggunakan kontrasepsi melainkan istri yang menggunakan kontrasepsi misal: pil, suntik, Implant, AKDR, MOW yaitu 40 orang (89\%), dan responden pengguna kondom yaitu empat orang $(9 \%)$, sedangkan suami tidak menggunakan kontrasepsi 
apapun (istri juga tidak menggunakan kontrasepsi) hanya satu orang (2\%), dan tidak ada orang yang menjadi pengguna kontrasepsi MOP.

2. Tingkat Pengetahuan Suami tentang Kontrasepsi Kondom

Tabel Distribusi Frekuensi Tingkat Pengetahuan Suami tentang Kontrasepsi Kondom di RW

\begin{tabular}{ccc} 
& XIII & \\
\hline Kontrasepsi Kondom & F & Prosentase (\%) \\
\hline Baik & 18 & 40 \\
Cukup & 26 & 57,88 \\
Kurang & 1 & 2,2 \\
\hline Jumlah & 45 & 100,00
\end{tabular}

Sumber : Data Primer

Berdasarkan tabel dapat diketahui bahwa Tingkat Pengetahuan Suami tentang Kontrasepsi Kondom di RW XIII sebagian besar adalah cukup yaitu 26 orang $(57,8 \%)$, tingkat pengetahuan baik 18 orang $(40 \%)$ dan tingkat pengetahuan kurang hanya satu orang saja $(2,2 \%)$.

3. Tingkat Pengetahuan Suami Tentang Kontrasepsi Kondom Berdasarkan Karakteristik Umur, Pendidikan, Pekerjaan, Alat Kontrasepsi yang Digunakan

a. Tingkat Pengetahuan Suami Tentang Kontrasepsi Kondom Berdasarkan Karakteristik Umur di RW XIII Kelurahan Sendangmulyo

\begin{tabular}{cccccc}
\hline & \multicolumn{3}{c}{ Tingkat Pengetahuan Suami Tentang } \\
& Kontrasepsi Kondom & \\
& Baik & Cukup & Kurang & Total \\
\hline $\mathbf{E}=\mathbf{2 0}$ tahun & 0 & 0 & 2 & 2 \\
$\mathbf{2 0 - 3 0}$ tahun & 21 & 9 & 1 & 31 \\
& $\mathbf{3 0}$ tahun & 5 & 7 & 0 & 12 \\
$\quad$ Total & 26 & 16 & 3 & 45 \\
\hline
\end{tabular}

Tabel tabulasi silang menunjukkan bahwa pada tingkatan umur $<20$ tahun mayoritas responden berpengetahuan kurang yaitu sebanyak 2 orang, pada umur 20-30 tahun mayoritas berpengetahuan baik yakni 21 orang, dan yang berumur $>30$ tahun mayoritas berpengetahuan cukup yaitu 7 orang.

b. Tingkat Pengetahuan Suami Tentang Kontrasepsi Kondom Berdasarkan Karakteristik Pendidikan di RW XIII Kelurahan Sendangmulyo

\begin{tabular}{llcccc}
\hline & & \multicolumn{4}{c}{ Tingkat Pengetahuan Suami } \\
& Tentang Kontrasepsi Kondom & \\
Baik & Cukup & Kurang & Total \\
\hline & Tidak sekolah & 0 & 0 & 0 & 0 \\
& Tamat SD & 0 & 0 & 1 & 1 \\
& Tamat SMP & 2 & 5 & 6 & 13 \\
& Tamat SMA & 18 & 2 & 0 & 20 \\
\hline
\end{tabular}




\begin{tabular}{lrcccc}
\hline & \multicolumn{4}{c}{ Tingkat Pengetahuan Suami } \\
& \multicolumn{2}{c}{ Tentang Kontrasepsi Kondom } & \\
& Baik & Cukup & Kurang & Total \\
\hline $\begin{array}{l}\text { Tamat } \\
\text { Perguruan Tinggi } \\
\text { Total }\end{array}$ & 11 & 0 & 0 & 11 \\
& Total & 7 & 7 & 45
\end{tabular}

Tabel tabulasi silang menunjukkan bahwa responden yang tidak bersekolah tidak ada. Dan responden yang tamat SD ada satu orang berpengetahuan kurang. Responden Tamat SMP mayoritas berpengetahuan kurang yaitu sebanyak 6 orang, namun yang berpengetahuan cukup sebanyak 5 orang. Tamat SMA semuanya berpengetahuan baik yaitu 11 orang.

c. Tingkat Pengetahuan Suami Tentang Kontrasepsi Kondom Berdasarkan Karakteristik Pekerjaan di RW XIII Kelurahan Sendangmulyo

\begin{tabular}{|c|c|c|c|c|c|}
\hline & & \multicolumn{3}{|c|}{$\begin{array}{c}\text { Tingkat Pengetahuan Suami Tentang } \\
\text { Kontrasepsi Kondom }\end{array}$} & \multirow[b]{2}{*}{ Tota } \\
\hline & & Baik & Cukup & Kurang & \\
\hline \multirow{4}{*}{ 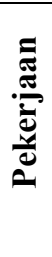 } & PNS & 15 & 1 & 0 & 16 \\
\hline & Swasta & 15 & 9 & 1 & 25 \\
\hline & Buruh & 0 & 1 & 3 & 4 \\
\hline & Total & 31 & 7 & 7 & 45 \\
\hline
\end{tabular}

Tabel tabulasi silang menunjukkan bahwa responden yang memiliki pekerjaan sebagai PNS mayoritas berpenegtahuan baik yaitu sebanyak 15 orang, berpengetahuan cukup 1 orang, dan berpengetahuan kurang tidak ada. Responden yang berpekerjaan Swasta mayoritas berpengetahuan baik 15 orang, cukup 9 orang, dan kurang 1 orang. Responden yang memiliki pekerjaan Buruh memiliki tingkat penegetahuan kurang sebanyak 4 orang, cukup 3 orang dan tidak ada yang berpengetahuan kurang.

d. Tingkat Pengetahuan Suami Tentang Kontrasepsi Kondom Berdasarkan Alat Kontrasepsi yang Digunakan di RW XIII Kelurahan Sendangmulyo

\begin{tabular}{|c|c|c|c|c|c|}
\hline & & \multicolumn{3}{|c|}{$\begin{array}{l}\text { Tingkat Pengetahuan Suami } \\
\text { Tentang Kontrasepsi Kondom }\end{array}$} & \multirow[b]{2}{*}{ Total } \\
\hline & & Baik & Cukup & Kurang & \\
\hline \multirow{3}{*}{ 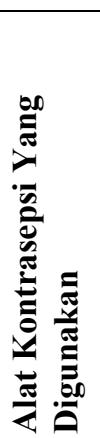 } & Kondom & 4 & 0 & 0 & 4 \\
\hline & MOP & 0 & 0 & 0 & 0 \\
\hline & $\begin{array}{l}\text { Suami tidak } \\
\text { menggunaka } \\
\text { n kontrasepsi } \\
\text { (istri yang } \\
\text { menggunaka } \\
\text { n) }\end{array}$ & 21 & 12 & 7 & 40 \\
\hline
\end{tabular}




\begin{tabular}{|c|c|c|c|c|c|}
\hline & $\begin{array}{l}\text { Suami dan } \\
\text { istri tidak } \\
\text { menggunaka } \\
\text { n } \\
\text { kontrasespsi } \\
\text { apapun }\end{array}$ & 0 & 1 & 0 & 1 \\
\hline Total & & 25 & 13 & 7 & 45 \\
\hline
\end{tabular}

Tabel tabulasi silang menunjukkan bahwa responden yang menggunakan alat kontrasepsi kondom memiliki tingkat penegetahuan yang baik semua yaitu sebanyak 4 orang. Tidak ada responden yang menggunakan alat kontrasepsi MOP. Untuk responden yang suami tidak menggunakan kontrasepsi melainkan istri yang menggunakan yaitu mayoritas berpengetahuan baik 21 orang, cukup 12 orang, dan kurang 7 orang. Sedangkan untuk responden yang suami dan istri tidak menggunakan kontrasepsi apapun berjumlah 1 orang, dan responden tersebut berpengetahuan cukup.

Responden pengguna kondom dalam penelitian ini sebanyak 4 orang. Dan semuanya berpengetahuan baik, disini responden tersebut sudah terpapar tentang kondom karena mereka menggunakan sendiri kontrasepsi tersebut. Maka mereka mengerti bagaimana keuntungan-keuntungan yang didapat dalam penggunaan kondom, bagaimana cara kerjanya, keefektifannya, dll, sehingga tahap pengetahuan responden tersebut sudah mencapai tahan evaluation, sehingga mereka sudah bisa menilai tentang kontrasepsi kondom. Pengguna kondom ini juga bisa memotivasi responden lainnya yang belum menggunakan kondom, yakni bisa diinformasikan tentang keuntungan kondom yang berfunsi ganda, yaitu selain bisa mencegah bertemunya sperma dan ovum, kondom juga bisa mencegah IMS-HIV/AIDS.

Untuk responden pengguna kontrasepsi MOP disini tidak ada. Untuk suami yang tidak menggunakan kontrasepsi melainkan istri yang menggunakan berpenegetahuan baik 21 orang cukup 12 orang, dan kurang 7 orang, dan yang suami dan istri tidak menggunakan kontrasepsi apapun hanya 1 orang berpengetahuan cukup. Hal ini disebabkan karena para responden belum pernah menggunakan sendiri kontrasepsi kondom, sehingga para responden tidak mengerti bagaiman kondom itu. Mereka hanya tahu dari informasi-informasi yang beredar.

\section{KESIMPULAN}

Responden yang menggunakan alat kontrasepsi kondom memiliki tingkat penegetahuan yang baik semua yaitu sebanyak 4 orang. Tidak ada responden yang menggunakan alat kontrasepsi MOP. Untuk responden yang suami tidak menggunakan kontrasepsi melainkan istri yang menggunakan yaitu mayoritas berpengetahuan baik 21 orang, cukup 12 orang, dan kurang 7 orang. Sedangkan untuk responden yang suami dan istri tidak menggunakan kontrasepsi apapun berjumlah 1 orang, dan responden tersebut berpengetahuan cukup.

\section{DAFTAR PUSTAKA}


Arikunto, S. (2006). Prosedur penelitian Suatu Pendekatan Praktek. Jakarta : PT. Reneka Cipta.

BKKBN. (2008). Umpan Balik Hasil Pelaksanaan Program Keluarga Berencana Nasional Jawa Tengah. Jawa Tengah : BKKBN.

Notoatmodjo, S. (2002). Metode Penelitian Kesehatan. Jakrta: PT. Rineka Cipta.

Notoatmodjo, S. (2003). Pendidikan Dan Perilaku Kesehatan. Jakarta : PT. Rineka Cipta.

Notoatmodjo, S. (2003). Ilmu Kesehatan Masyarakat. Jakarta : PT. Rineka Cipta.

Nursalam, SP. (2003). Konsep dan Penerapan Metode Penelitian Ilmu Keperawatan. Jakarta : Salemba Medika.

Sugiyono. (20060. Statistika Untuk Penelitian. Bandung: Alfa Beta.

Yayasan Bina Pustaka Sarwono, (2006). Panduan Praktis Pelayanan Kontrasepsi. Jakarta : BKKBN.

BKKBN. (2009). http://prov.bkkbn.go.id/gemapria/article.php?catid=2, diakses tanggal 7 Desember 2010

Hasan. (2009). http://ardhana12.wordpress.com/2008/02/08/teknik-analisis-datadalam-penelitian/, diakses tanggal 8 Desember 2010

Laskar. (2006). http://www.hupelita.com/baca.php?id=43502, diakses tanggal 8 Desember 2010

Mardiyo. (2009). http://artikelindonesia.com/kontrasepsi-kondom-bagi-pria.html, diakses tanggal 7 Desember 2010 